DOI 10.37882/2500-3682.2021.06.09

\title{
КРИЗИС ИДЕНТИЧНОСТИ И ЕЕ СВЯЗЬ С ТОЛЕРАНТНОСТЬЮ К НЕОПРЕДЕЛЕННОСТИ
}

\section{IDENTITY CRISIS AND ITS RELATION TO THE TOLERANCE TO AMBIGUITY}

M. Kuzmin

E. Mironova

A. Kiseleva

E. Filinova

O. Osipenok

Summary: The article analyzes the problem of the relationship between tolerance to ambiguity and identity crisis among women of different ages. The author analyzes the degree of development of the problem of this connection in domestic and foreign literature. On a sample of 412 subjects aged $18-75$ years using the different methods the author reveals both the features of tolerance to ambiguity in women of different ages, and the nature of its relationship with indicators of identity crisis in women. It is shown that, although the relationship between tolerance to ambiguity and identity crisis is negative in the entire sample, there is a specificity of this relationship depending on age. The causes of non-linear communication are analyzed.

Keywords: tolerance to ambiguity, identity, women, identity crisis.

\author{
Кузьмин Михаил Юрьевич \\ к.nсх.н., доцент, ФГБОУ ВО «Иркутский \\ государственный университет» \\ mirroy@mail.ru \\ Миронова Елена Ивановна \\ Старший преподаватель, ФГБОУВО «Иркутский \\ государственный университет» \\ Киселева Анастасия Андреевна \\ Старший методист, Институт развития образования \\ Иркутской области \\ nk160493@gmail.com \\ Филинова Елизавета Андреевна \\ ФГБОУ ВО «Иркутский государственный университет» \\ liza.filinova44@gmail.com \\ Осипенок Оксана Александровна \\ к.n.н., дочент, ФГБОУ ВО «Иркутский \\ государственный университет» \\ cominagetcha@mail.ru
}

Аннотация: В статье анализируется проблема связи толерантности к неопределенности и кризиса идентичности на выборке женщин различного возраста. Автор анализирует степень разработанности проблемы данной связи в отечественной и зарубежной литературе. На выборке в 412 испытуемых в возрасте 18-75 лет при помощи методик «СЭИ-тест» Е.Л. Солдатовой, «0просник кризисной идентичности», Шкалы толерантности к неопределенности MSTAT-II и Шкалы депрессии А. Бека автор выявляет как особенности толерантности к неопределенности у женщин различного возраста, так и характер ее связи с показателями кризиса идентичности у женщин. Показано, что, если на всей выборке связь между толерантностью к неопределенности и кризисом идентичности имеет отрицательный характер, однако существует специфика этой связи в зависимости от возраста. Анализируются причины нелинейной связи.

Ключевые слова: толерантность к неопределенности, идентичность, женщины, кризис идентичности.

преодоления продолжают вестись как отечественными, так и зарубежными учеными.

Одним из направлений такого поиска является анализ личностных свойств и образований, препятствующих развитию кризиса идентичности. Ими могут выступать ощущение субъективного благополучия [Pavot \& Diener, 1993], стратегии совладающего поведения [Белинская, 2019], [Luyckx et. al., 2005] и др. Еще одним личностным свойством, препятствующим развитию кризиса идентичности, является толерантность к неопределенности. Определяемая как феномен, позволяющий личности успешно функционировать в непредсказуемом пространстве [Kraus, 1995], толерантность к неопределенности характеризуется поиском ситуации неопределен- 
ности, чувством комфорта в момент пребывания в ней, способностью размышлять над проблемой, даже если не известны все факты и возможные последствия принятого решения и способностью принимать конфликт и напряжение, которые возникают в ситуации двойственности и др. [Лазо, 2015].

В ряде работ ([Fuchs, 2007 ], [Scoggin, 1996], [Oyserman, 2010] рассматриваются частные случаи связи кризиса идентичности и толерантности к неопределенности - В ситуации фрагментации идентичности [Fuchs, 2007], кризиса профессиональной идентичности [Scoggin, 1996] или - шире - социального ее компонента [Oyserman, 2010]. На наш взгляд, необходим более подробный, всесторонний анализ, рассматривающий связь толерантности к неопределенности и различных сторон идентичности, находящейся в кризисе (эмоциональной, поведенческой, собственно эго-идентичности и др.). Мы предполагаем, что определение таких связей позволит в дальнейшем лучше понять, в каких случаях толерантность к неопределенности может являться условием преодоления кризиса идентичности.

С учетом этого, мы поставили целью проанализировать связь толерантности к неопределенности и различных проявлений кризиса идентичности.

\section{Материалы и методы исследования}

Исследование проводилось в период с декабря 2018 по декабрь 2019 на базе ФГБНУ НЦ Проблем здоровья семьи и репродукции человека (г. Иркутск). Выборку исследования составили женщины в возрасте 18-75 лет общим числом 412 человек, проходивших плановый медосмотр. Возрастные особенности испытуемых представлены на Таблице 1.

Для изучения толерантности к неопределенности использовалась шкала MSTAT-II D.L. McLain [McLain, 2009] в адаптации Д.А. Леонтьева, Е.Н. Осина и Е.Г. Луковицкой [Леонтьев, Осин, Луковицкая, 2016]. Идентичность изучалась при помощи методик «СЭИ-тест» Е.Л. Солдатовой [Солдатова, 2007], Оценка кризиса идентичности «Опросник кризисной идентичности» [Дмитриева, Перевозкин, Перевозкина, Самойлик, 2012] и методика Шкала депрессии А. Бека А. [по Елшанский, Ануфриев, Ефимова, Семенов, 2016]. Обработка полученных данных осуществлялась с помощью критерия корреляции $r$ Пирсона и Н-критерия Крускала-Уоллеса. Вычисления осуществлялись в программе SPSS 23.0. Критической величиной уровня значимости считалось $p<0,01$, значимости на уровне тенденции - $\mathrm{p}<0,05$.

\section{Результаты и обсужкение}

На первом этапе мы установили уровень толерантности к неопределенности нашей выборки. Оказалось, что он составил 48, стандартное отклонение - 10,1. Таким образом, испытуемые женщины продемонстрировали средний уровень толерантности к неопределенности.

На втором этапе мы проанализировали связи между показателями кризиса идентичности женщин и уровнем их толерантности к неопределенности.

Во-первых, при анализе связей шкалы толерантности к неопределенности и методики «Оценка кризиса идентичности» было выявлено следующее. Оказалось, что су-

Таблица 1.

Возрастные особенности испытуемых

\begin{tabular}{|c|c|c|c|c|c|c|}
\hline Возраст & $18-27$ & $28-35$ & $36-41$ & $42-49$ & $50-55$ & старше 55 \\
\hline Число & 41 & 74 & 68 & 89 & 64 & 76 \\
\hline$\%$ & $9,95 \%$ & $17,96 \%$ & $16,50 \%$ & $21,60 \%$ & $15,53 \%$ & $18,45 \%$ \\
\hline
\end{tabular}

Таблица 2. Корреляционные связи между шкалами методики Оценка кризиса идентичности и методики MSTAT-II

\begin{tabular}{|c|c|c|c|c|c|c|c|c|}
\hline Шкалы & ДСО ${ }^{1}$ & ЦСА & $\ni A^{3}$ & $\Pi A^{4}$ & МП1 & $C A^{6}$ & $C \Phi^{7}$ & $C Ж^{8}$ \\
\hline MSTAT-II & $-0,019$ & $-0,275^{*}$ & $-0,233^{*}$ & $-0,410^{* *}$ & $-0,308^{* *}$ & $-0,233^{*}$ & $-0,100$ & 0,025 \\
\hline & & $\begin{array}{r}\text { *. Koppe } \\
\text { *. Koppe } \\
\text { - } \\
{ }^{5} \text { - Mex }\end{array}$ & $\begin{array}{r}\text { я значи } \\
\text { 1я значи } \\
\text { о-родит } \\
\text { - Ценно } \\
3 \text { - Эм } \\
4 \text { - По } \\
\text { ностны } \\
6 \text { - С } \\
7 \text { - С } \\
\text { - Соци }\end{array}$ & $\begin{array}{l}\text { ға уровн } \\
\text { на уровю } \\
\text { ские, сел } \\
\text {-смысл } \\
\text { рнальнь } \\
\text { енчески } \\
\text { офесси } \\
\text { альный } \\
\text { совые ф } \\
\text { тая жела }\end{array}$ & $\begin{array}{l}5 \text { (двухс } \\
01 \text { (двух } \\
\text { ые отно } \\
\text { 1 аспект } \\
\text { пект } \\
\text { пект } \\
\text { иьные от } \\
\text { ект } \\
\text { ры } \\
\text { ьность }\end{array}$ & $\begin{array}{l}\text { онняя). } \\
\text { онняя) } \\
\text { ния } \\
\text { јения }\end{array}$ & & \\
\hline
\end{tabular}


ществуют отрицательные связи между шкалой МСТАТ-2 и основными шкалами методики ОКИ. Так, шкала МСТАТ-2 негативно связана с Ценностно-смысловым аспектом $(r=-0,275, p=0,042)$, Эмоциональным аспектом ( $r=-0,23$, $\mathrm{p}=0,05)$, Поведенческим аспектом ( $r=-0,41, \mathrm{p}=0,01)$, Межличностными и профессиональными отношениями ( $\mathrm{r}=-$ $0,3, p=0,01)$ и Сексуальным аспектом ( $r=-0,23, p=0,042)$. Получается, что чем ниже у испытуемых выражена толерантность к неопределенности, тем более выражены такие проявления кризиса идентичности, как пониженная самооценка, трудности в самоопределении, смысловой вакуум, неудовлетворенность своей сексуальной жизнью, профессиональная неудовлетворенность, рост тревожности и депрессивных проявлений.

Последнее обстоятельство подтверждается и при анализе связей шкалы толерантности к неопределенности и шкалы депрессии А. Бека. Оказалось, что чем выше у испытуемых выражена шкала MSTAT-II, тем ниже у них проявление депрессии - причем как ее когнитивно-аффективного $(r=-0,2, p=0,01)$, так и соматического $(r=-0,19$, $\mathrm{p}=0,01)$, компонентов.

Наконец, анализ связей толерантности к неопределенности и кризисных проявлений в эго-идентичности выявил следующее. Оказалось, что чем выше у испытуемых выражена шкала МСТАТ, тем выше у них выражен статус Достигнутой идентичности $(r=0,36, p=0,01)$ и, наоборот, ниже статус Спутанной идентичности ( $r=-0,35$, $\mathrm{p}=0,01)$. Получается, что испытуемые, обладающие зрелой эго-идентичностью, скорее демонстрируют толерантность к неопределенности. Со статусом Предрешенной идентичности связей не обнаружено.

При этом с субшкалами методики СЭИ-тест наибольшая корреляция приходится на шкалы Творческая сила развития ( $r=0,36$ для Достигнутой идентичности и $r=-0,37$ для статуса Спутанной; $p=0,01)$ и Сила Эго ( $r=0,36$ для Достигнутой идентичности и $\mathrm{r}=-0,37$ для статуса Спутанной, $\mathrm{p}=0,01)$.

Таким образом, можно сделать следующие выводы. В целом, чем ниже у испытуемых женщин выражена толерантность к неопределенности, тем выше у них выраженность различных проявлений кризиса идентичности, затрагивающих как эго-идентичность, так и другие ее компоненты. У женщин с низкой толерантностью к неопределенности наблюдается пониженная самооценка, трудности в самоопределении, смысловой вакуум, неудовлетворенность своей сексуальной жизнью, профессиональная неудовлетворенность, рост тревожности и депрессивных проявлений.

Мы предположили так же, что особенности связи толерантности к неопределенности и кризиса идентичности могут быть обусловлены возрастом. В одном из предыдущих наших исследований [Кузьмин и др., 2019] мы отмечали, что эго-идентичность имеет свои особенности на различных возрастных этапах. Поэтому на третьем этапе мы проанализировали особенности связи толерантности к неопределенности и кризиса идентичности у женщин с учетом их возраста.

Таблица 3.

Результаты испытуемых женщин различного возраста по методике MSTAT-II

\begin{tabular}{|c|c|c|}
\hline Возраст & M & SD \\
\hline $18-27$ & 51,38 & 8,07 \\
\hline $28-35$ & 51,69 & 10,33 \\
\hline $36-41$ & 47,03 & 9,53 \\
\hline $42-49$ & 47,24 & 8,81 \\
\hline $50-55$ & 44,14 & 10,96 \\
\hline старше 55 & 46,59 & 12,93 \\
\hline
\end{tabular}

Как следует из таблицы, с возрастом наблюдается постепенное снижение показателя толерантности к неопределенности у женщин (исключая некоторый рост в возрасте старше 55-ти лет). Данный факт подтверждается статистически: $\mathrm{H=14,3,} \mathrm{p-0,014.} \mathrm{Таким} \mathrm{образом,} \mathrm{чем}$ моложе женщина, тем выше у нее толерантность к неопределенности.

Далее мы проанализировали характер связи шкалы толерантности к неопределенности и шкал, отражающих особенности кризиса идентичности у женщин различного возраста.

Анализируя связи между шкалой толерантности к неопределенности и шкалами методики СЭИ-тест на женщинах различного возраста, можно обнаружить следующее: чем первоначально выше у девушек 18-27 лет уровень толерантности к неопределенности, тем ниже уровень Достигнутой идентичности и выше - Спутанной ( $r=-0,296$ и $r=0,365$ соответственно, $p=0,01$ ); начиная с периода 28-35 лет характер связи меняется: обнаруживается обратная корреляция между уровнем толерантности к неопределенности и Спутанной идентичностью (в диапазоне от -0,18 в возрасте старше 55-ти лет до -0,298 в возрасте 36-41 год); появляется положительная связь с Предрешенной идентичностью (характерна для возраста 28-35 лет и 42-49 лет).

Таким образом, говоря о связи эго-идентичности и толерантности к неопределенности, можно предположить, что ее характер обусловлен возрастом. Если у молодых девушек и женщин (18-27 лет) толерантность к неопределенности сопровождается большей выраженностью статуса Спутанной идентичности и меньшей - Достигнутой, то в дальнейшем, наоборот, чем больше выражена толерантность к неопределенности, 
тем меньше - Спутанная идентичность. Можно предположить, что высокая толерантность к неопределенности в возрасте 18-27 лет препятствует самоопределению девушек т.к. открывает слишком много возможностей для идентификации.

При этом связь между шкалой депрессии А. Бека и толерантностью к неопределенности на всех возрастных этапах имеет отрицательный характер как для основной шкалы, так и для шкал Когнитивно-аффективной и Соматической (особенно в возрасте 42-55 лет). Таким образом, вне зависимости от возраста высокая толерантность к неопределенности связана с низким проявлением когнитивно-аффективных признаков депрессии, а, начиная с 42-х лет - и соматических проявлений. В последнем случае можно предполагать, что толерантность к неопределенности позволяет легче их переживать.

Наконец, связи шкалы толерантности к неопределенности и шкал методики «Оценка кризиса идентич- ности» имеют следующие особенности. Так, шкала Ценностно-смысловой аспект (ЦСА) положительно связана с толерантностью к неопределенности только у девушек в возрасте 18-27 лет - на других возрастных этапах данная связь имеет отрицательный характер. Шкалы Эмоциональный аспект (ЭА), Поведенческий аспект (ПА) и Межличностные и профессиональные отношения (МПО) связаны с толерантностью к неопределенности только отрицательно: эта связь усиливается с возрастом до 5055 лет. Наконец, шкала Сексуальный аспект (СА) демонстрирует отрицательные корреляции (на уровне $\mathrm{r}=-0,28$ ) только в возрастных диапазонах 18-27 и 36-41 год.

Таким образом, существуют особенности связи толерантности к неопределенности с различными сферами, которые затрагивает кризис идентичности, в зависимости от возраста. Так, у молодых девушек и женщин 1827 лет выраженная толерантность к неопределенности сопровождается не только ростом Спутанности идентичности, но и выраженностью ценностно-смыслового

Корреляционные связи между шкалами методики MSTAT-II и шкалами других методик

Таблица 4. у женщин различного возраста

\begin{tabular}{|c|c|c|c|c|c|c|}
\hline Возраст & $18-27$ & $28-35$ & $36-41$ & $42-49$ & $50-55$ & старше 55 \\
\hline Шкалы & MSTAT-II & MSTAT-II & MSTAT-II & MSTAT-II & MSTAT-II T & MSTAT-II \\
\hline Достигнутая & $-0,296^{* *}$ & 0,043 & $0,236^{* *}$ & 0,005 & 0,105 & 0,144 \\
\hline Спутанная & $0,365^{* *}$ & $-0,195^{*}$ & $-0,298^{* *}$ & $-0,215^{*}$ & $-0,298^{* *}$ & $-0,188^{*}$ \\
\hline Предрешенная & $-0,034$ & $0,219^{*}$ & 0,165 & $0,290^{* *}$ & 0,154 & 0,050 \\
\hline Когнитивно-аффективная & $-0,200^{*}$ & $-0,071$ & $-0,262^{* *}$ & $-0,250^{* *}$ & $-0,555^{* *}$ & $-0,085$ \\
\hline Соматическая & $-0,060$ & $-0,134$ & $-0,098$ & $-0,175^{*}$ & $-0,452^{* *}$ & $-0,010$ \\
\hline $\mathrm{BDI}^{1}$ & $-0,173^{*}$ &,- 096 & $-0,247^{* *}$ & $-0,257^{* *}$ & $-0,574^{* *}$ & $-0,070$ \\
\hline $\mathrm{ACO}$ & $-0,09$ & $-0,011$ & $-0,019$ & 0,08 & $-0,011$ & $-0,011$ \\
\hline$\left\lfloor C A^{3}\right.$ & $0,280^{* *}$ & 0,11 & $-0,245$ & $-0,281^{* *}$ & $-0,19^{*}$ & 0,15 \\
\hline$\exists A^{4}$ & $-0,25^{* *}$ & $-0,311^{* *}$ & $-0,213^{*}$ & $-0,313^{* *}$ & $-0,288^{* *}$ & $-0,111$ \\
\hline$\Pi A^{5}$ & 0,11 & $-0,21^{*}$ & $-0,48^{* *}$ & $-0,39^{* *}$ & $-0,24^{* *}$ & $-0,21^{*}$ \\
\hline МП० ${ }^{6}$ & $-0,008$ & $-0,22^{*}$ & $-0,208^{*}$ & $-0,218^{*}$ & $-0,25^{* *}$ & $-0,11$ \\
\hline$C A^{7}$ & $-0,288^{* *}$ & $-0,08$ & $-0,241^{* *}$ & $-0,141$ & $-0,14$ & $-0,02$ \\
\hline$C \Phi^{8}$ & $-0,01$ & $-0,08$ & $-0,09$ & $-0,05$ & $-0,12$ & $-0,08$ \\
\hline$C \nVdash^{9}$ & 0,025 & 0,015 & 0,014 & 0,011 & 0,04 & $-0,053$ \\
\hline & $\begin{array}{r}{ }^{*} \text {. Koppe } \\
{ }^{* *} \text {. Koppe } \\
{ }^{2}-\text { Д } \\
{ }^{6}-\text { Mer }\end{array}$ & $\begin{array}{r}\text { значим } \\
\text { значим } \\
1 \text { - Шка } \\
\text {-родител } \\
\text { Ценност } \\
4 \text { - Эмоц } \\
5 \text { - Повє } \\
\text { остные, } \\
7 \text { - Сек } \\
8 \text { - Стр } \\
\text { - Социал }\end{array}$ & $\begin{array}{l}\text { овне 0,0 } \\
\text { овне 0, } \\
\text { рессии Б } \\
\text { семейн } \\
\text { лсловой } \\
\text { ьный ас } \\
\text { ский асг } \\
\text { ссионал } \\
\text { ыый аспе } \\
\text { Іе факто } \\
\text { яелатель }\end{array}$ & $\begin{array}{l}\text { хсторон } \\
\text { хсторон } \\
\text { ошения } \\
\text { т } \\
\text { тношен }\end{array}$ & & \\
\hline
\end{tabular}


аспекта кризиса идентичности. Как мы предполагали выше, это может быть вызвано повышенными возможностями в поиске своего места в жизни: испытывая меньшую тревогу относительно характера своей жизни, легче переживая неопределенность, таким девушкам, как ни парадоксально, сложнее «найти себя». При этом на других возрастных этапах особенности связи толерантности к неопределенности и кризиса идентичности принципиально не меняются; речь идет лишь об усилении отдельных связей.

Таким образом, на третьем этапе мы обнаружили следующее.

Во-первых, с возрастом у женщин наблюдается постепенное снижение показателя толерантности к неопределенности. Соответственно, чем моложе женщина, тем выше у нее данный показатель.

Во-вторых, оказалось, что существует возрастная специфика связи толерантности к неопределенности и показателей кризиса идентичности. Особенно примечательной она оказывается для женщин и девушек в возрасте 18-27 лет.

В литературе мы не нашли исследований, отражающих гендерную, равно как и возрастную специфику толерантности к неопределенности. Выглядит логичным, что с возрастом толерантность к неопределенности снижается, а личность становится более консервативной.

Что касается специфики связей толерантности к неопределенности и показателей кризиса идентичности, то тут можно отметить ряд особенностей. В литературе отмечается, что с возрастом кризисные проявления в идентичности снижаются. Так, по данным P. Fadjukoff, L. Pulkkinen, и K. Kokko [Fadjukoff, Pulkkinen, Kokko, 2016], с возрастом женщины идут по пути все большей доли достигнутой идентичности и все меньшей - диффузной. Эта тенденция затрагивает различные аспекты жизни: религиозные убеждения, политические предпочтения, карьеры, интимно-личностных отношений и образа жизни. Авторы обнаружили, что женщины, как правило, численно превосходят мужчин по степени выраженности достигнутой идентичности на более ранних возрастных этапах. Однако, ближе к 50-ти, гендерные различия уменьшились в большинстве областей (исключая религиозной составляющей, где мужчины демонстрируют спутанную идентичность). Аналогично, по результатам J. Kroger, M. Martinussen \& J. Marcia, статус Достигнутой идентичности так же возрастает до 30-36 лет, а статус Моратория, наоборот, снижается [Kroger, Martinussen Marcia, 2010]. В работе Е.Л. Солдатовой так же показано, что в кризисные возрастные периоды показатели автономной идентичности (A) возрастают, а диффузной (C) - снижаются [Солдатова, 2007].

В данном исследовании мы не проводили углубленный анализ динамики кризиса идентичности у женщин различного возраста. Однако в другой работе [Кузьмин, Миронова, Осипенок, 2019] отмечалась специфика выраженности идентичности у женщин в кризисные и межкризисные возрастные периоды. Этим может объясняться различный характер связи между толерантностью к неопределенности и показателями кризиса идентичности.

\section{Зак^ючение}

Целью данного исследования было определение особенностей связи толерантности к неопределенности и различных проявлений кризиса идентичности. В ходе него было установлено следующее.

Во-первых, чем ниже у испытуемых женщин выражена толерантность к неопределенности, тем выше у них выраженность различных проявлений кризиса идентичности, затрагивающих как эго-идентичность, так и другие ее компоненты. У женщин с низкой толерантностью к неопределенности наблюдается пониженная самооценка, трудности в самоопределении, смысловой вакуум, неудовлетворенность своей сексуальной жизнью, профессиональная неудовлетворенность, рост тревожности и депрессивных проявлений.

Во-вторых, с возрастом у женщин наблюдается постепенное снижение показателя толерантности к неопределенности. Соответственно, чем моложе женщина, тем выше у нее данное свойство.

Наконец, оказалось, что существует возрастная специфика связи толерантности к неопределенности и показателей кризиса идентичности. Если у молодых девушек и женщин (18-27 лет) толерантность к неопределенности сопровождается большей выраженностью статуса Спутанной идентичности и меньшей - Достигнутой, то в дальнейшем, наоборот, чем больше выражена толерантность к неопределенности, тем меньше - Спутанная идентичность. Можно предположить, что высокая толерантность к неопределенности в возрасте 18-27 лет препятствует самоопределению девушек т.к. открывает слишком много возможностей для идентификации.

Полученные результаты могут быть использованы как основа для дальнейшего исследования данной проблемы (в частности, с учетом социо-демографических факторов и их влияния на связь толерантности к неопределенности и кризиса идентичности), так и в практической деятельности при учете воспитательной работы в организациях средне-специального и высшего образования. 


\section{ЛИТЕРАТУРА}

1. Андреева Г.М. К вопросу о кризисе идентичности в условиях социальных трансформаций [Электронный ресурс] // Психологические исследования: электрон. науч. журн. - 2011. - № 6(20). - URL: http://psystudy.ru (дата обращения: 01.03.2021).

2. Белинская Е.П. Особенности идентичности личности и стратегии совладающего поведения // Междисциплинарные ресурсы экономической психологии в формировании этнорегиональной идентичности и позитивного образа малой родины: материалы Всерос. науч.-практ. конф. с междунар. участием. Иркутск, 27-30 июня, 2019 г. [отв. ред.: А.Д. Карнышев, В.А. Решетников]; ФГБОУ ВО «ИГУ», - Иркутск: Изд-во ИГУ, 2019. - 609 с.

3. Дмитриева Н.В., Перевозкин С.Б., Перевозкина Ю.М., Самойлик Н.А. Диагностика Кризиса идентичности. Новокузнецк: РИО КузГПА, 2012.134 с.

4. Елшанский С.П., Ануфриев А.Ф., Ефимова О.С., Семенов Д.В. Особенности ретестовой надежности шкалы депрессии А. Бека // Психология, социология и педагогика. - 2016. - № 4 [Электронный ресурc]. URL: http://psychology.snauka.ru/2016/04/6649 (дата обращения: 11.04.2021).

5. Кузьмин М.Ю., Миронова Е.И., Осипенок О.А. Особенности идентичности женщин в кризисные и межкризисные возрастные периоды // Российский психологический журнал. - 2019. - Т. 16. - № 3. - С. 72-86. D0I: 10.21702/rpj.2019.3.6.

6. Лазо Н.Н. Личностный потенциал лиц, осуществляющих руководство в образовании (на примере толерантности к неопределенности) // Психология и педагогика: методика и проблемы практического применения. - 2015. - №43. - С. 12-17.

7. Леонтьев Д.А., Осин Е.Н., Луковицкая Е.Г. Диагностика толерантности к неопределенности: Шкалы Д. Маклейна. М.: Смысл. 2016. 60 с.

8. Солдатова Е.Л. Структура и динамика нормативного кризиса перехода к взрослости: монография. Челябинск: Изд-во ЮУрГУ, 2007. 267 с.

9. Fadjukoff P., Pulkkinen L., Kokko K (2016). Identity formation in adulthood: A longitudinal study from age 27 to 50 . Identity: An International Journal of Theory and Research, №16, 8-23. D0I: 10.1080/15283488.2015.1121820.

10. Fuchs T (2007). Fragmented Selves: Temporality and Identity in Borderline Personality Disorder. Psychopathology, 40(6), 379-387. D0l:10.1159/000106468.

11. Kraus A (1995). Psychotherapy Based on Identity Problems of Depressives. American Journal of Psychotherapy, №49 (2), 197- 212. D0I:10.1176/appi. psychotherapy.1995.49.2.197.

12. Kroger J., Martinussen M., Marcia J. E (2010). Identity status change during adolescence and young adulthood: A meta-analysis. Journal of Adolescence, № 33, 683-698. D0I: 10.1016/j.adolescence.2009.11.002.

13. Luyckx K., Goossens L., Soenens B., Beyers W., Vansteenkiste M. (2005). Identity statuses based on 4 rather than 2 identity dimensions: Extending and refining Marcia's paradigm. Journal of Youth and Adolescence, 34, 605-618.

14. McLain D.L. (2009) Evidence of the Properties of an Ambiguity Tolerance Measure: The Multiple Stimulus Types Ambiguity Tolerance Scale-II (MSTAT-II). Psychological Reports, №105(3), 975-988. D01:10.2466/pr0.105.3.975-988.

15. Oyserman D., Destin M. (2010). Identity-Based Motivation: Implications for Intervention. The Counseling Psychologist, №38(7), 1001-1043. DOI: $10.1177 / 0011000010374775$.

16. Pavot W., Diener E. (1993). Review of the Satisfaction with Life Scale. Psychological Assessment, 5(2), 164-172. https://doi.org/10.1037/1040-3590.5.2.164.

17. Scoggin J. (1996). How nurse-midwives define themselves in relation to nursing, medicine, and midwifery. Journal of Nurse-Midwifery, №41(1), 36-42. D0l:10.1016/0091-2182(95)00063-1.

18. Shamionov R.M. (2018). Attitude to change and tolerance to uncertainty as predictors of adaptability and adaptive readiness. Russian Psychological Journal, №14(2), 90-104. https://doi.org/10.21702/rpj.2017.2.5

19. Vindeker O.S., Klimenskikh, M.V. (2018). Psychometric facets of Antifragility: Tolerance of Ambiguity, Hardiness, and Growth. Russian Psychological Journal, №13(3), 107-122. https://doi.org/10.21702/rpj.2016.3.7

( Кузьмин Михаил Юрьевич (mirroy@mail.ru), Миронова Елена Ивановна, Киселева Анастасия Андреевна (nk160493@gmail.com), Филинова Елизавета Андреевна (liza.filinova44@gmail.com), Осипенок Оксана Александровна (cominagetcha@mail.ru).

Журнал «Современная наука: актуальные проблемы теории и практики» 